\author{
Сергей В. Скрыль ${ }^{1}$, Елена В. Смирнова ${ }^{2}$, Александр В. Заряев ${ }^{3}$, \\ Ле Ву Хыонг Занг ${ }^{4}$, Анжелика С. Хмелина ${ }^{5}$ \\ ${ }_{1,2,5}$ Федеральное государственное бюджетное образовательное учреждение высшего образования \\ «Московский государственный технический университет имени Н.Э. Баумана \\ (национальный исследовательский университет)» (МГТУ им. Н.Э. Баумана) \\ ул. 2-я Бауманская, 5, Москва, 105005, Россия \\ ${ }^{3}$ Государственный научно-исследовательский испытательный институт проблем технической \\ защиты информации Федеральной службы по техническому и экспортному контролю, \\ ул. 9 Января, 280а, Воронеж, 3940209, Россия \\ ${ }^{4}$ Center of Quality Assurance Ho Chi Minh City University of Economics and Finance (UEF), Viet Nam, \\ 141-145, Dien Bien Phu St., W.15, Binh Thanh Dist., HCMC \\ ${ }^{1}$ e-mail: karel105@mail.ru, https://orcid.org/0000-0002-4309-6255 \\ ${ }^{2}$ e-mail: bmstu.smirnova@gmail.com, https://orcid.org/0000-0003-2275-3276 \\ ${ }^{3}$ e-mail: zaryaev@yandex.ru, https://orcid.org/0000-0003-1316-8032 \\ ${ }^{4}$ e-mail: gianglvh@uef.edu.vn, https://orcid.org/0000-0003-4990-0731 \\ ${ }^{5}$ e-mail: anjel.hmelina2010@yandex.ru, https://orcid.org/0000-0002-3517-1235

\section{СИСТЕМАТИЗАЦИЯ ХАРАКТЕРИСТИК ЗАЩИЩЕННОСТИ ОБРАЗОВАТЕЛЬНОЙ ДЕЯТЕЛЬНОСТИ ПО ПОДГОТОВКЕ СПЕЦИАЛИСТОВ В ОБЛАСТИ ИНФОРМАЦИОННОЙ БЕЗОПАСНОСТИ DOI: http://dx.doi.org/10.26583/bit.2020.4.03}

Аннотация. В статье обосновывается возможность распространения закономерностей, характерных для информационного процесса, на образовательный процесс. Рассматриваются особенности проявления свойства защищенности информации в условиях образовательной деятельности, связанной с подготовкой специалистов в области информационной безопасности. Анализируются недостатки оценки данного свойства количественными методами. Обосновывается возможность оценки защищенности образовательной деятельности качественными методами. Определяются классификационные основания для систематизации характеристик защищенности. Приводится структура характеристик защищенности образовательной деятельности по подготовке специалистов в области информационной безопасности. Формулируются методические положения для реализации процедуры синтеза данной структуры. Приводятся варианты характеристических таблиц и пример таблицы решений для оценки значений характеристик защищенности образовательной деятельности в терминах лингвистической шкалы. Полученные результаты позволят практически оценить целесообразность проведения мероприятий по обеспечению безопасности информации в процессе образовательной деятельности. Разработанная методика может рассматриваться как методическое обеспечение решения задачи оценки защищенности образовательной деятельности.

Ключевые слова: подготовка спечиалистов, информационная безопасность, защищенность образовательной деятельности, количественные методы оценки, качественные методы оченки, структура характеристик защищенности образовательной деятельности.

Для иитирования: СКРЫЛЬ, Сергей В. и др. СИСТЕМАТИЗАЦИЯ ХАРАКТЕРИСТИК ЗАЩИЩЕННОСТИ ОБРАЗОВАТЕЛЬНОЙ ДЕЯТЕЛЬНОСТИ ПО ПОДГОТОВКЕ СПЕЦИАЛИСТОВ В ОБЛАСТИ ИНФОРМАЦИОННОЙ БЕЗОПАСНОСТИ. Безопасность информационных технологий, [S.l.], v. 27, n. 4, p. 25-36, 2020. ISSN 2074-7136. Доступно на: <https://bit.mephi.ru/index.php/bit/article/view/1303>. Дата docmyna: 19 nov. 2020. DOI: http://dx.doi.org/10.26583/bit.2020.4.03.

Sergey V. Skryl ${ }^{11}$, Elena V. Smirnova ${ }^{2}$, Alexandr V. Zaryaev ${ }^{3}$, Le Vu Huong Giang ${ }^{4}$, Anzhelika S. Khmelina ${ }^{5}$

${ }^{1,2,5}$ Federal State Educational Institution of Higher Education «Bauman Moscow State Technical University», 2nd Bauman str., 5, Moscow, 105005, Russia

${ }^{3}$ State research and testing Institute of problems of technical protection of information of the FSTEC of Russia, 
Сергей В. Скрыль, Елена В. Смирнова, Александр В. Заряев,

Ле Ву Хыонг Занг, Анжелика С. Хмелина

СИСТЕМАТИЗАЦИЯ ХАРАКТЕРИСТИК ЗАЩИЩЕННОСТИ ОБРАЗОВАТЕЛЬНОЙ ДЕЯТЕЛЬНОСТИ ПО ПОДГОТОВКЕ СПЕЦИАЛИСТОВ В ОБЛАСТИ ИНФОРМАЦИОННОЙ БЕЗОПАСНОСТИ

\author{
9 on January str., 280a, Voronezh, 394020, Russia \\ ${ }^{4}$ Center of Quality Assurance Ho Chi Minh City University of Economics and Finance (UEF), Viet Nam, \\ 141-145, Dien Bien Phu St., W.15, Binh Thanh Dist., HCMC \\ ${ }^{1}$ e-mail: karel105@mail.ru, https://orcid.org/0000-0002-4309-6255 \\ ${ }^{2}$ e-mail: bmstu.smirnova@gmail.com, https://orcid.org/0000-0003-2275-3276 \\ 3e-mail:zaryaev@yandex.ru, https://orcid.org/0000-0003-1316-8032 \\ ${ }^{4}$ e-mail: gianglvh@uef.edu.vn, https://orcid.org/0000-0003-4990-0731 \\ ${ }^{5}$ e-mail: anjel.hmelina2010@yandex.ru, https://orcid.org/https://orcid.org/0000-0002-3517-1235
}

\title{
Systematization of security characteristics of educational activities for training specialists in the field of information security \\ DOI: http://dx.doi.org/10.26583/bit.2020.4.03
}

Abstract. The possibility of extending the patterns characteristic of the information process to the educational process is substantiated in this paper. The features of the manifestation of information security properties in the context of educational activities related to the training of specialists in the field of information security are considered. The disadvantages of evaluating this property by quantitative methods are analyzed. It substantiates the possibility of assessing the security of educational activity by qualitative methods. Classification grounds for systematization of security characteristics are determined. The structure of the characteristics of the security of educational activities for the training of specialists in the field of information security is given. Methodological provisions for the implementation of the synthesis procedure of this structure are formulated. Variants of characteristic tables and an example of a decision table for assessing the values of the security characteristics of educational activities in terms of a linguistic scale are given. The results obtained will allow us to assess the feasibility of carrying out measures practically to ensure the information security of educational activities. The developed method can be considered as a methodological support for solving the practical problem of assessing the security of educational activities.

Keywords: specialists training, information security, security of educational activities, quantitative assessment methods, qualitative assessment methods, structure of characteristics of educational activity security.

For citation: SKRYL', Sergey V. et al. Systematization of security characteristics of educational activities for training specialists in the field of information security. IT Security (Russia), [S.l.], v. 27, n. 4, p. 25-36, 2020. ISSN 2074-7136. Available at: 〈https://bit.mephi.ru/index.php/bit/article/view/l303〉. Date accessed: 19 nov. 2020. doi: http://dx.doi.org/10.26583/bit.2020.4.03.

\section{Введение}

Методологический уровень теоретических основ информатики, как результата практики развития информационных технологий позволяет сформировать понятийный базис для понимания одной из фундаментальных категорий информатики - категории «информационный процесс» [1]. Широта восприятия всех аспектов данного понятия позволяет распространить закономерности реализации процедур накопления, обработки и передачи информации на такой специфичный вид деятельности как образовательная. Анализ этой деятельности, информационной по своей сути, позволяет выявить в процедурах накопления знаний, их усвоения и передачи целый ряд свойств, характерных для образовательного процесса, как процесса информационного. Речь идет о полноте, адекватности, целостности и своевременности реализации процедур образовательной деятельности [2]. Это, в свою очередь, позволило разработать целый ряд математических моделей для количественной оценки перечисленных характеристик [3] и предложить вариант интегральной количественной оценки качества подготовки специалистов $[4,5]$.

Вместе с тем при оценке качества такой специфичной, но весьма важной сферы деятельности, как подготовка специалистов в области информационной безопасности, следует учитывать и тот факт, что на качество образовательного процесса оказывает 
существенное влияние информационная характеристика «защищенность», а значит, необходимо исследовать возможности оценки количественными методами качества защиты информации в образовательном процессе [6]. Вместе с тем, несмотря на существующую практику количественной оценки отдельных характеристик образовательного процесса [3, 7], применение количественных методов для оценки защищенности образовательного процесса сопряжено с рядом трудностей, перечисленных в [8]. Главной причиной этих трудностей является довольно большое число слабо формализуемых факторов проявления угроз безопасности информации в рамках образовательной деятельности, и отсутствие возможности определения их влияния на ее обеспечение в рамках количественной шкалы оценки.

Указанные трудности использования количественных методов для оценки защищенности образовательного процесса обусловили необходимость поиска таких подходов к оценке данной характеристики, которые учитывали бы особенности влияния угроз безопасности информации на виды обеспечения образовательной деятельности [9]. В этих условиях одним из возможных путей оценки защищенности образовательной деятельности является синтез комплексного показателя, характеризующего возможности образовательных учреждений, осуществляющих подготовку специалистов в области информационной безопасности, по реализации мер защиты информации от угроз ее безопасности.

В работе [10] предложен принципиально новый подход к решению проблемы оценки защищенности образовательной деятельности в процессе подготовки специалистов в области информационной безопасности, суть которого состоит в систематизации разнородных проявлений эффекта реагирования на воздействие угроз безопасности информации и синтеза структуры характеристик защищенности такого рода информационной деятельности. Принципиальным здесь является то обстоятельство, что проявление эффекта от принимаемых мер защиты информации можно оценить лишь в качественных терминах $[11,12]$.

\section{1. Принципы формирования структуры характеристик защищенности образовательной деятельности в процессе подготовки специалистов в области информационной безопасности}

В общем виде процедура синтеза структуры характеристик защищенности образовательной деятельности сводится к упорядочению множества проявлений эффекта реагирования на воздействие угроз безопасности информации в процессе такого рода деятельности [13]. При этом упорядочение осуществляется в соответствии с определенными классификационными основаниями, а сама структура является композиционной структурой, уровни которой соответствуют этим основаниям.

Классификационными основаниями для упорядочения множества проявлений эффекта реагирования на воздействие угроз безопасности информации в процессе образовательной деятельности являются возможности по оценке:

1) состояний защищенности информации в процессе реализации образовательной деятельности;

2) защищенности информации о видах обеспечения образовательного и воспитательного процесса;

3) безопасности информации в процессе реализации основных компонент образовательных технологий;

4) целевого назначения принимаемых мер защиты информации от воздействия угроз ее безопасности в процессе образовательной деятельности [14-16]. 
На рис. 1 представлена структура характеристик защищенности образовательной деятельности по подготовке специалистов в области информационной безопасности.

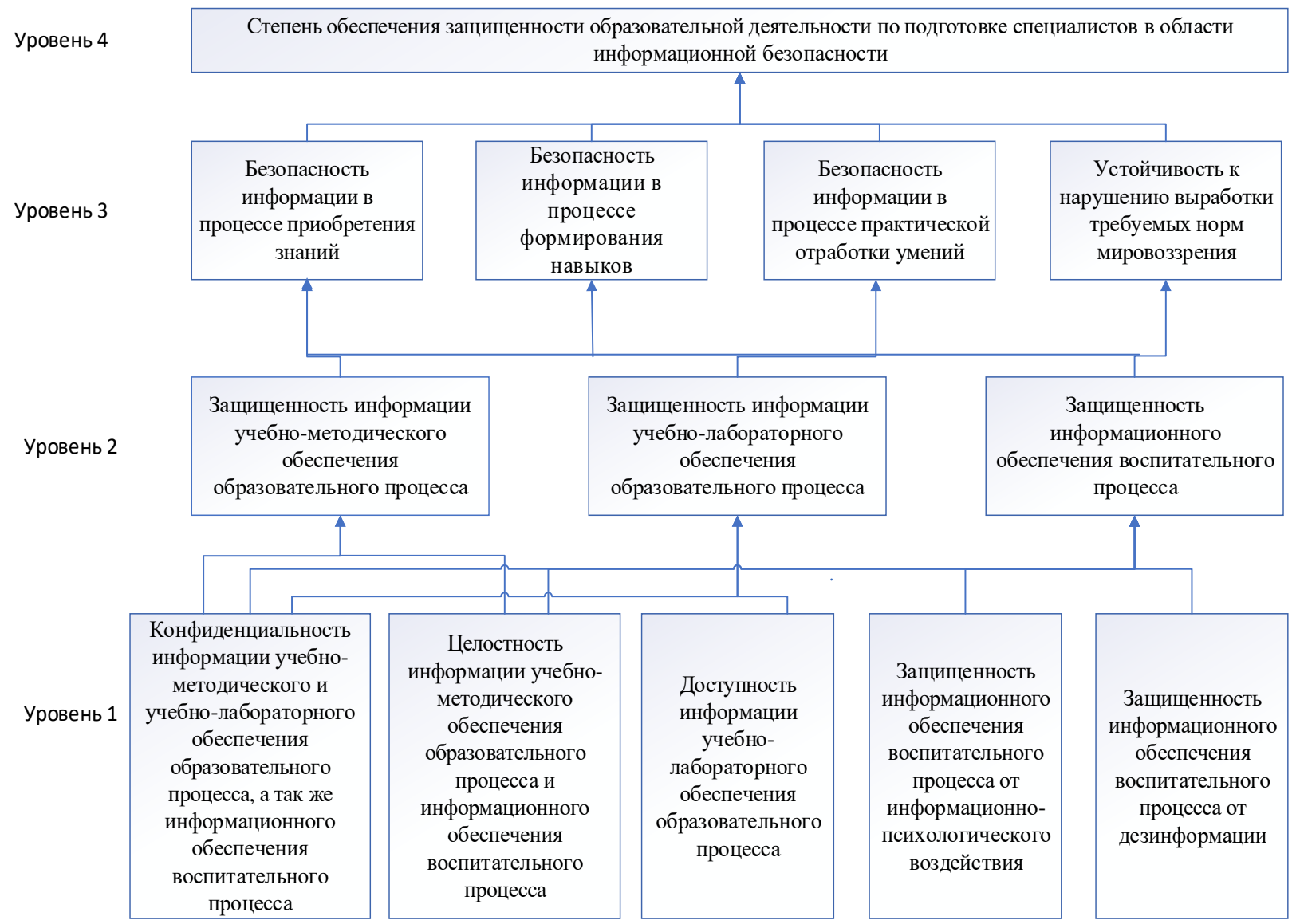

Рис. 1. Структура характеристик защищенности образовательной деятельности по подготовке специалистов в области информационной безопасности

(Fig. 1. Structure of security characteristics of educational activities for training specialists in the field of information security)

Характеристикой, классифицируемой как целевая, является степень обеспечения защищенности образовательной деятельности по подготовке специалистов в области информационной безопасности.

Процедура синтеза структуры характеристик защищенности образовательной деятельности в процессе подготовки специалистов в области информационной безопасности реализуется с учетом следующих методических положений.

1. Характеристика целевого назначения принимаемых мер защиты информации от воздействия угроз безопасности информации в процессе образовательной деятельности является системной характеристикой ее защищенности и должна представляться единым системным показателем.

2. Единый системный показатель формируется на основе характеристик, классифицируемых в соответствии с приведенными выше основаниями в порядке их убывания.

3. Структура формируемой системы характеристик является многоуровневой. Ее уровни соответствуют рассмотренным выше классификационным основаниям.

4. Композиционная процедура формирования структуры характеристик защищенности образовательной деятельности в процессе подготовки специалистов в 
области информационной безопасности реализуется в следующей последовательности:

1) формирование характеристик защищенности информации видов обеспечения образовательного и воспитательного процесса путем установления композиционных отношений между характеристиками обеспечения состояний защищенности информации в процессе реализации образовательной деятельности;

2) формирование характеристик безопасности информации в процессе реализации основных компонент образовательных технологий путем установления композиционных отношений между характеристиками защищенности информации видов обеспечения образовательного и воспитательного процесса;

3) формирование показателя защищенности образовательной деятельности в процессе подготовки специалистов в области информационной безопасности путем установления композиционных отношений между характеристиками безопасности информации в процессе реализации основных компонент образовательных технологий.

Таким образом, очевидно, что исходными при синтезе структуры характеристик защищенности образовательной деятельности в процессе подготовки специалистов в области информационной безопасности являются характеристики обеспечения состояний защищенности. Определим эти характеристики как первичные. Остальные характеристики будут считаться производными от первичных и определяются как вторичные.

Композиционные отношения «многие ко многим» в синтезируемой структуре являются отношениями между разнотипными характеристиками, а композиционные отношения «многие к одному» являются отношениями, образуемыми в результате приведения разнотипных характеристик к однотипным. Логика этих отношений представляется в лингвистических терминах. Оценка этих характеристик осуществляется в рамках однотипной качественной шкалы в терминах лингвистических переменных.

Оценка первичных характеристик осуществляется экспертными методами при помощи характеристических таблиц, а оценка остальных характеристик и системного показателя осуществляется формальными методами с помощью таблиц решений.

\section{2. Методический аппарат лингвистической оценки качества подготовки специалистов в области информационной безопасности}

При формировании характеристических таблиц для оценки характеристик обеспечения состояний защищенности информации в процессе реализации образовательной деятельности [11] будем полагать, что первичная характеристика обладает:

- свойством конфиденциальности информации учебно-методического и учебнолабораторного обеспечения образовательного процесса, a также информационного обеспечения воспитательного процесса, если всесторонне обеспечиваются функции противодействия техническим каналам утечки конфиденциальной информации, которую получают студенты в процессе накопления знаний, формирования навыков и практической отработки умений по работе со средствами защиты информации;

- свойством целостности информации учебно-методического обеспечения образовательного процесса и информационного обеспечения воспитательного процесса, если обеспечивается требуемый уровень достоверности информации в процессе накопления знаний, формирования навыков и практической отработки умений по работе со средствами рассматриваемого типа;

- свойством доступности информации учебно-лабораторного обеспечения образовательного процесса, если невозможно затруднение ее использования в процессе формирования навыков и практической отработки умений работы со средствами 
защиты информации;

- свойством защищенности информационного обеспечения воспитательного процесса от информационно-психологического воздействия, если всесторонне реализуются функции контроля нарушений, вызванных с навязыванием чуждых идеологических и социальных установок, формирования ложных стереотипов поведения, трансформации настроений, чувств и воли студентов при выработке у них стиля мышления, обладателя правосознания и менталитета, духовных идеалов и ценностных установок, типичных для носителя требуемых норм мировоззрения;

- свойством защищенности информационного обеспечения воспитательного процесса от дезинформации, если всесторонне реализуются функции защиты от навязывания ложной информации.

Характерные признаки первичных свойств выявляются в результате анализа возможностей принимаемых мер защиты информации [15] по обеспечению состояний ее защищенности в процессе реализации образовательной деятельности и оцениваются следующими лингвистическими переменными:

OB (очень высокая) - все принимаемые меры защиты информации с данным признаком (свойством) являются эффективными;

В (высокая) - подавляющее большинство принимаемых мер защиты информации с данным признаком (свойством) являются эффективными;

ВC (выше среднего) - практически все принимаемые меры защиты информации с данным признаком (свойством) являются эффективными;

C (средняя) - некоторые принимаемые меры защиты информации с данным признаком (свойством) являются эффективными;

НC (ниже среднего) - отдельные принимаемые меры защиты информации с данным признаком (свойством) являются эффективными;

Н (низкая) - меры защиты информации принимаются;

ОН (очень низкая) - меры защиты информации не принимаются.

В табл. 1-5 приводятся варианты характеристических оценок защищенности информации в процессе подготовки специалистов в области информационной безопасности.

Таблица 1. Характеристические оценки конфиденциальности информации учебнометодического и учебно-лабораторного обеспечения образовательного прочесса, а также информационного обеспечения воспитательного прочесса

\begin{tabular}{|l|c|}
\hline \multicolumn{2}{|c|}{ Характеризуемое свойство и состояния его обеспеченности } \\
\hline \multicolumn{2}{|c|}{ Представление документированных требований к реализации мер обеспечения } \\
конфиденциальности информации
\end{tabular}


Сергей В. Скрыль, Елена В. Смирнова, Александр В. Заряев,

Ле Ву Хыонг Занг, Анжелика С. Хмелина

СИСТЕМАТИЗАЦИЯ ХАРАКТЕРИСТИК ЗАЩИЩЕННОСТИ ОБРАЗОВАТЕЛЬНОЙ ДЕЯТЕЛЬНОСТИ ПО ПОДГОТОВКЕ СПЕЦИАЛИСТОВ В ОБЛАСТИ ИНФОРМАЦИОННОЙ БЕЗОПАСНОСТИ

\begin{tabular}{|c|c|}
\hline \multicolumn{2}{|c|}{ Таблицза 1 (окончание) } \\
\hline Характеризуемое свойство и состояния его обеспеченности & Оценка \\
\hline $\begin{array}{l}\text { Реализуются лишь процедуры разграничения полномочий по функциям доступа } \\
\text { к информации, включая процедуры идентификации фактов нарушения } \\
\text { полномочий доступа }\end{array}$ & $\mathrm{BC}$ \\
\hline $\begin{array}{l}\text { Реализуются лишь процедуры разграничения полномочий по доступу к части } \\
\text { данных, включая процедуры идентификации фактов нарушения полномочий } \\
\text { доступа }\end{array}$ & $\mathrm{C}$ \\
\hline 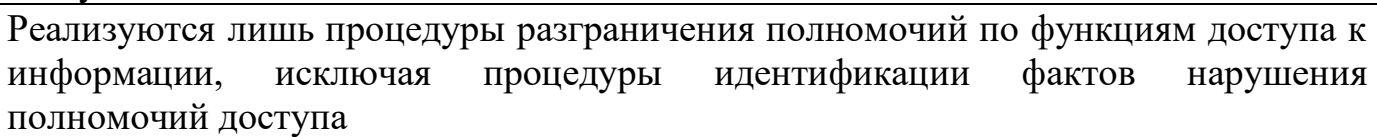 & $\mathrm{HC}$ \\
\hline $\begin{array}{l}\text { Реализуются лишь процедуры разграничения полномочий по доступу к части } \\
\text { данных, включая процедуры идентификации фактов нарушения полномочий } \\
\text { доступа }\end{array}$ & $\mathrm{H}$ \\
\hline Процедуры не реализуются & $\mathrm{OH}$ \\
\hline \multicolumn{2}{|l|}{ Реализуемость функций защиты информации от утечки по техническим каналам } \\
\hline $\begin{array}{l}\text { Функции реализуются в отношении всех возможных каналов утечки информации } \\
\text { через побочные электромагнитные излучения и наводки (ПЭМИН) в пределах } \\
\text { всей контролируемой зоны, включающей учебные помещения и помещения со } \\
\text { средствами вычислительной техники (CВТ), работающими с программными } \\
\text { средствами специального назначения }\end{array}$ & $\mathrm{OB}$ \\
\hline $\begin{array}{l}\text { Функции реализуются в отношении всех каналов утечки информации через } \\
\text { ПЭМИН, исключая программно управляемое ПЭМИН, в пределах всей } \\
\text { контролируемой зоны, включающей учебные помещения и помещения с СВТ, } \\
\text { работающими с программными средствами специального назначения }\end{array}$ & $\mathrm{B}$ \\
\hline $\begin{array}{l}\text { Функции реализуются в отношении побочных электромагнитных излучений } \\
\text { (ПЭМИ) в пределах контролируемой зоны, включающей помещения с СВТ, } \\
\text { работающими с программными средствами специального назначения }\end{array}$ & $\mathrm{BC}$ \\
\hline $\begin{array}{l}\text { Функции реализуются в отношении наводок электромагнитных излучений (ЭМИ) } \\
\text { в пределах контролируемой зоны, включающей помещения с СВТ, работающими } \\
\text { с программными средствами специального назначения }\end{array}$ & $\mathrm{C}$ \\
\hline $\begin{array}{l}\text { Функции реализуются в части защиты информации от утечки по каналам ПЭМИН } \\
\text { по отношению к отдельным СВТ, работающими с программными средствами } \\
\text { специального назначения }\end{array}$ & $\mathrm{HC}$ \\
\hline $\begin{array}{l}\text { Функции реализуются в части защиты информации от утечки по каналам ПЭМИ } \\
\text { по отношению к отдельным СВТ, работающими с программными средствами } \\
\text { специального назначения }\end{array}$ & $\mathrm{H}$ \\
\hline Функции отсутствуют & $\mathrm{OH}$ \\
\hline
\end{tabular}

Таблицуа 2. Характеристические оценки ичелостности информацчи учебно-методического обеспечения образовательного процесса и информационного обеспечения воспитательного

\begin{tabular}{|c|c|}
\hline Характеризуемое свойство и состояние его обеспеченности & Оценка \\
\hline \multicolumn{2}{|c|}{$\begin{array}{c}\text { Выполнение функций контроля достоверности и целостности информации } \\
\text { при реализации образовательного и воспитательного процесса }\end{array}$} \\
\hline Функции выполняются постоянно & OB \\
\hline $\begin{array}{l}\text { Функции контроля достоверности } \quad \text { информации } \quad \text { выполняются } \\
\text { a функции контроля целостности информации - по команде }\end{array}$ & B \\
\hline $\begin{array}{l}\text { Функции контроля достоверности информации выполняются по команде, } \\
\text { а функции контроля целостности информации - постоянно }\end{array}$ & $\mathrm{BC}$ \\
\hline $\begin{array}{l}\text { Функции контроля достоверности и целостности информации выполняются } \\
\text { по команде }\end{array}$ & $\mathrm{C}$ \\
\hline
\end{tabular}


Сергей В. Скрыль, Елена В. Смирнова, Александр В. Заряев,

Ле Ву Хыонг Занг, Анжелика С. Хмелина

СИСТЕМАТИЗАЦИЯ ХАРАКТЕРИСТИК ЗАЩИЩЕННОСТИ ОБРАЗОВАТЕЛЬНОЙ ДЕЯТЕЛЬНОСТИ ПО ПОДГОТОВКЕ СПЕЦИАЛИСТОВ В ОБЛАСТИ ИНФОРМАЦИОННОЙ БЕЗОПАСНОСТИ

\begin{tabular}{|c|c|}
\hline \multicolumn{2}{|c|}{ Таблица 2 (окончание) } \\
\hline Характеризуемое свойство и состояние его обеспеченности & Оценка \\
\hline $\begin{array}{l}\text { Функции контроля достоверности информации выполняются по команде, контроль } \\
\text { целостности информации отсутствует }\end{array}$ & $\mathrm{HC}$ \\
\hline $\begin{array}{l}\text { Функции контроля целостности информации выполняются по команде, контроль } \\
\text { достоверности информации отсутствует }\end{array}$ & $\mathrm{H}$ \\
\hline Функции контроля достоверности и целостности информации отсутствуют & $\mathrm{OH}$ \\
\hline \multicolumn{2}{|l|}{$\begin{array}{c}\text { Выполнение функций восстановления целостности информации } \\
\text { при реализации образовательного и воспитательного процесса }\end{array}$} \\
\hline $\begin{array}{l}\text { Имеются в наличии полные копии учебно-методического обеспечения } \\
\text { образовательного процесса и информационного обеспечения воспитательного } \\
\text { процесса }\end{array}$ & $\mathrm{B}$ \\
\hline $\begin{array}{l}\text { Имеется в наличии полная копия учебно-методического } \\
\text { образовательного процесса и непечения } \\
\text { воспитательного процесса }\end{array}$ & $\mathrm{C}$ \\
\hline $\begin{array}{l}\text { Имеется в наличии полная копия информационного обеспечения воспитательного } \\
\text { процесса и неполная копия учебно-методического обеспечения образовательного } \\
\text { процесса }\end{array}$ & $\mathrm{H}$ \\
\hline $\begin{array}{l}\text { Имеются в наличии неполные копии учебно-методического обеспечения } \\
\text { образовательного процесса и информационного обеспечения воспитательного } \\
\text { процесса }\end{array}$ & $\mathrm{OH}$ \\
\hline
\end{tabular}

Таблиияа 3. Характеристические оценки доступности информации учебно-лабораторного обеспечения образовательного процесса

\begin{tabular}{|c|c|}
\hline Характеризуемое свойство и состояние его обеспеченности & Оценка \\
\hline \multicolumn{2}{|c|}{$\begin{array}{c}\text { Реализуемость функций контроля блокирования доступа к устройствам СВТ, } \\
\text { работающих с программными средствами специального назначения }\end{array}$} \\
\hline $\begin{array}{l}\text { Реализованы функции контроля блокирования доступа к устройствам, портам и } \\
\text { сетевому оборудованию СВТ }\end{array}$ & OB \\
\hline $\begin{array}{l}\text { Реализованы функции контроля блокирования доступа к сетевому оборудованию } \\
\text { СВТ }\end{array}$ & $\mathrm{B}$ \\
\hline $\begin{array}{l}\text { Реализованы функции контроля блокирования доступа к процессорному устройству } \\
\text { СВТ }\end{array}$ & $\mathrm{BC}$ \\
\hline Реализованы функции контроля блокирования доступа к памяти СВТ & $\mathrm{C}$ \\
\hline Реализованы функции контроля блокирования доступа к портам СВТ & $\mathrm{HC}$ \\
\hline $\begin{array}{l}\text { Реализованы функции контроля блокирования доступа к устройствам ввода/вывода } \\
\text { информации СВТ }\end{array}$ & $\mathrm{H}$ \\
\hline $\begin{array}{l}\text { Отсутствуют функции контроля блокирования доступа к устройствам } \mathrm{CBT,} \\
\text { работающих с программными средствами специального назначения }\end{array}$ & $\mathrm{OH}$ \\
\hline \multicolumn{2}{|l|}{$\begin{array}{c}\text { Своевременность реагирования на блокирование доступа к устройствам СВТ, } \\
\text { работающих с программными средствами специального назначения }\end{array}$} \\
\hline Время реагирования не превышает 5 минут & $\mathrm{B}$ \\
\hline Время реагирования не превышает 15 минут & $\mathrm{C}$ \\
\hline Время реагирования не превышает часа & $\mathrm{H}$ \\
\hline Время реагирования превышает час & $\mathrm{OH}$ \\
\hline
\end{tabular}

На основе полученных при помощи характеристических таблиц 1-5 значений характеристик обеспечения состояний защищенности информации в процессе реализации образовательной деятельности определяются характеристики защищенности информации видов обеспечения образовательного и воспитательного процесса. Для этого используются соответствующие таблицы решений. 
Сергей В. Скрыль, Елена В. Смирнова, Александр В. Заряев,

Ле Ву Хыонг Занг, Анжелика С. Хмелина

СИСТЕМАТИЗАЦИЯ ХАРАКТЕРИСТИК ЗАЩИЩЕННОСТИ ОБРАЗОВАТЕЛЬНОЙ ДЕЯТЕЛЬНОСТИ ПО ПОДГОТОВКЕ СПЕЦИАЛИСТОВ В ОБЛАСТИ ИНФОРМАЦИОННОЙ БЕЗОПАСНОСТИ

Таблищуа 4. Характеристические оцуенки защчищенности информационного обеспечения воспитательного процесса от информационно-психологического воздействия Характеризуемое свойство и состояние его обеспеченности

Оценка

Реализуемость функций контроля нарушений процесса выработки у студентов требуемых норм мировоззрения

Реализованы функции постоянного контроля со стороны руководства учебных подразделений

Реализованы функции контроля по планам подразделений, осуществляющих воспитательную работу

Установлен периодический контроль над влиянием всех средств информационнопсихологического воздействия на сознание студента как носителя требуемых норм мировоззрения

Установлен периодический контроль над влиянием агитационной деятельности общественных организаций, политических партий, кандидатов в политические лидеры на сознание студента как носителя требуемых норм мировоззрения

Установлен периодический контроль над влиянием средств массовой информации на сознание студента как носителя требуемых норм мировоззрения

Установлен периодический контроль над влиянием виртуально-психологических средств на сознание студента как носителя требуемых норм мировоззрения Функции контроля нарушений процесса выработки у студента требуемых норм мировоззрения реализуются лишь по последствиям информационнопсихологического воздействия

Реализуемость функций контроля признаков дезинформации в информационном обеспечении воспитательного процесса

Реализуются подразделением, осуществляющим воспитательную работу

Реализуются учебным управлением образовательного учреждения

Реализуются должностными лицами

Реализуются руководством учебных подразделений

Реализуются режимным подразделением

Реализуются профильной кафедрой

Не реализуются

OB

$\mathrm{B}$

$\mathrm{BC}$

$\mathrm{C}$

$\mathrm{HC}$

$\mathrm{H}$

$\mathrm{OH}$

Таблий 5. Характеристические оценки защчищенность информационного обеспечения воспитательного прочесса от дезинформации

Состояние обеспеченности характеризуемого свойства

Мероприятия по выявлению и блокированию источников угроз дезинформации реализуются

Мероприятия по выявлению и блокированию источников угроз дезинформации

не реализуются

$\mathrm{H}$

Примером таблицы решений для оценки защищенности информации учебнометодического обеспечения образовательного процесса является таблица 6.

Аналогичным образом строятся таблицы решений для оценки всех остальных вторичных характеристик защищенности образовательной деятельности по подготовке специалистов в области информационной безопасности, включая показатель защищенности.

Из изложенного следует, что результативность предложенного методического подхода к оценке защищенности образовательной деятельности по подготовке специалистов в области информационной безопасности является предпосылкой его практического использования. 
Таблицуа 6. Оиченка защчищченности информащзи учебно-методического обеспечения образовательного процесса

\begin{tabular}{|c|c|c|}
\hline \multicolumn{2}{|c|}{ 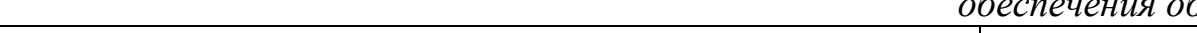 } & \multirow[b]{2}{*}{$\begin{array}{c}\text { Оценка } \\
\text { защищенности } \\
\text { информации учебно- } \\
\text { методического } \\
\text { обеспечения }\end{array}$} \\
\hline $\begin{array}{c}\text { Наименование характеристик обеспечения состояний } \\
\text { защищенности информации }\end{array}$ & Оценка & \\
\hline $\begin{array}{l}\text { Представление документированных требований к } \\
\text { реализации мер обеспечения конфиденциальности } \\
\text { информации }\end{array}$ & $\mathrm{BC}$ & \multirow{5}{*}{$\mathrm{BC}$} \\
\hline $\begin{array}{l}\text { Реализуемость процедур разграничения полномочий } \\
\text { доступа к информации при работе с программными } \\
\text { средствами специального назначения }\end{array}$ & $\mathrm{C}$ & \\
\hline $\begin{array}{l}\text { Реализуемость функций защиты информации от утечки } \\
\text { по техническим каналам }\end{array}$ & $\mathrm{BC}$ & \\
\hline $\begin{array}{l}\text { Выполнение функций } \\
\text { целостности информации }\end{array}$ & B & \\
\hline $\begin{array}{l}\text { Выполнение } \\
\text { информации }\end{array}$ & B & \\
\hline
\end{tabular}

\section{Заключение}

В статье обоснован и практически реализован методический подход к оценке защищенности образовательной деятельности по подготовке специалистов в области информационной безопасности на основе систематизации характеристик возможностей по обеспечению безопасности информации в процессе такого рода деятельности.

Разработана методика систематизации характеристик возможностей по обеспечению безопасности информации в процессе образовательной деятельности по подготовке специалистов в области информационной безопасности. В соответствии с данной методикой предложено:

- совокупность характеристик возможностей по обеспечению безопасности информации в процессе образовательной деятельности по подготовке специалистов в области информационной безопасности представлять в виде иерархической структуры с последовательным обобщением этих возможностей

- уровни данной структуры представлять в виде подмножеств характеристик, соответствующих определенным классификационным основаниям;

- в качестве аппарата для формализации логики оценок целесообразно использовать характеристические таблицы и таблицы решений.

Полученные результаты позволяют практически оценить целесообразность проведения мероприятий по обеспечению безопасности информации в процессе образовательной деятельности по подготовке специалистов в области информационной безопасности.

Разработанная методика может рассматриваться как методическое обеспечение решения практической задачи оценки защищенности образовательной деятельности по подготовке специалистов в области информационной безопасности.

Предложенный в статье методический подход позволяет исследовать деятельность по обеспечению безопасности информации в широком диапазоне параметров. 
Сергей В. Скрыль, Елена В. Смирнова, Александр В. Заряев,

Ле Ву Хыонг Занг, Анжелика С. Хмелина

СИСТЕМАТИЗАЦИЯ ХАРАКТЕРИСТИК ЗАЩИЩЕННОСТИ ОБРАЗОВАТЕЛЬНОЙ ДЕЯТЕЛЬНОСТИ ПО ПОДГОТОВКЕ СПЕЦИАЛИСТОВ В ОБЛАСТИ ИНФОРМАЦИОННОЙ БЕЗОПАСНОСТИ

СПИСОК ЛИТЕРАТУРЫ:

1. Булдакова Т.И., Карпенко А.П., Рудаков И.В. Особенности подготовки кадров по информатике и вычислительной технике / В сборнике: Перспективные направления развития отечественных информационных технологий. Материалы IV межрегиональной научно-практической конференции. Севастопольский государственный университет; науч. ред. Б.В. Соколов. 2018. С. 339-341.

2. Скрыль С.В., Ле Ву Хыонг Занг, Нгуэн Тхань Ньян. Показатели эффективности процесса подготовки специалистов // Вестник Воронежского института МВД России. - Воронеж: Воронежский институт МВД России, 2015. №. 3. С. 64-71. URL: https://cyberleninka.ru/article/n/pokazateli-effektivnosti-protsessapodgotovki-spetsialistov/viewer (дата обращения: 07.10.2020).

3. Скрыль С.В., Пономарев В.А., Хыонг Занг Ле Ву. Математические модели комплексной оценки качества деятельности по подготовке специалистов технического профиля в высших учебных заведениях. // Промышленные АСУ и контроллеры. - М: Научтехлитиздат, 2016. №10. С. 8-16. URL: https://elibrary.ru/item.asp?id=27180767 (дата обращения: 07.10.2020)

4. Зеленцова Е.В., Ле Ву Хыонг Занг и др. Методические положения по реализации процедур систематизации характеристик качества подготовки специалистов // Научный взгляд: труды международной научно-практической конференции. - М.: Московский государственный областной университет, 2015. С. 225-230.

5. Скрыль С.В., Ле Ву Хыонг Занг и др. Структура системы характеристик качества деятельности по подготовке специалистов в высших учебных заведениях // Промышленные АСУ и контроллеры. - М: «Научтехлитиздат», 2016. №9. С. 11-15. URL: https://elibrary.ru/item.asp?id=26702710 (дата обращения: 07.10.2020).

6. Dortman, Svetlana, Информационная безопасность ребенка, как субъекта образовательного процесса /Защита детства: проблемы, поиски, решения // Сборник материалов Всероссийской научнопрактической конференции, приуроченной к Десятилетию детства в России. 2018. С. $315-319$. URL: $\quad$ https://ssrn.com/abstract=3469614 2 (дата DOI: http://dx.doi.org/10.25791/asu.1.2020.1118.

7. Скрыль С.В. и др. Математическая модель для оценки эффективности подготовки специалистов по информационной безопасности на основе временных характеристик образовательного процесса // Промышленные АСУ и контроллеры. - M: «Научтехлитиздат», 2020. №1. С. $28-35$. DOI: http://dx.doi.org/10.25791/asu.1.2020.1118.

8. Надеждин Е.Н., Шептуховский В.А. Методика оценивания рисков информационной безопасности в вычислительных сетях образовательных учреждений // Педагогическая информатика. 2012. № 4. С. 84-92.

9. Надеждин Е.Н., Шептуховский В.А. Алгоритмический подход к оценке рисков информационной безопасности образовательных учреждение // Научный поиск. 2013. №2.5. С. 23-27.

10. Щербаков Н. П. Совершенствование системы оценки качества высшего образования /Н.П. Щербаков // Гарантии качества профессионального образования: тезисы докладов международной научнопрактической конференции / [редкол.: Я.Л. Овчинников и др.]. Барнаул: Изд-во АлтГТУ, 2015. С. 9-11.

11. Гузаиров М.Б., Машкина И.В., Степанова Е.С. Построение модели угроз с помощью нечетких когнитивных карт на основе сетевой политики безопасности // Безопасность информационных технологий. 2011. №2. С. 37-49.

12. Rabai L.B., Rjaibi N., Aissa A.B. (2012) Quantifying security threats for E-learning systems. DOI: http://dx.doi.org/10.1109/ICEELI.2012.6360592.

13. Skryl' S. et al. (2019) Assessing the Response Timeliness to Threats as an Important Element of Cybersecurity: Theoretical Foundations and Research Model. In: Kravets A., Groumpos P., Shcherbakov M., Kultsova M. (eds) Creativity in Intelligent Technologies and Data Science. CIT\&DS 2019. Communications in Computer and Information Science, vol 1084. Springer, Cham. DOI: https://doi.org/10.1007/978-3-030-29750-3_20.

14. Долженко А.И., Потапов Л.И. Анализ информационной безопасности образовательного процесса университета на базе нечетких моделей / SOFT MEASUREMENTS AND COMPUTING. Vol. 30, No. 5, 2020. P. 32-40. URL: https://elibrary.ru/item.asp?id=43929605 (дата обращения: 20.10.2020).

15. Горбатов, Виктор Сергеевич и др. Постановка задачи по реализации доверенного сеанса связи при дистанционном обучении. Безопасность информационных технологий, [S.1.]. Т. 20, № 3. C. 104-105, 2013. ISSN 2074-7136. URL: https://bit.mephi.ru/index.php/bit/article/view/328 (дата обращения: 07.10.2020).

16. Тулиганова Л.Р., Павлова И. А., Машкина И.В. Разработка моделей объекта защиты и угроз нарушения безопасности в информационной системе, базирующейся на технологии виртуализации // Известия ЮФУ. Технические науки № 8 (157). - Таганрог: Изд-во ТТИ ЮФУ, 2014. С. 32-41. 
Сергей В. Скрыль, Елена В. Смирнова, Александр В. Заряев,

Ле Ву Хыонг Занг, Анжелика С. Хмелина

СИСТЕМАТИЗАЦИЯ ХАРАКТЕРИСТИК ЗАЩИЩЕННОСТИ ОБРАЗОВАТЕЛЬНОЙ ДЕЯТЕЛЬНОСТИ ПО ПОДГОТОВКЕ СПЕЦИАЛИСТОВ В ОБЛАСТИ ИНФОРМАЦИОННОЙ БЕЗОПАСНОСТИ

\section{REFERENCES:}

[1] Buldakova T.I., Karpenko A.P., Rudakov I.V. Features of training in computer science and engineering. In the collection: Perspective directions of development of domestic information technologies. materials of the IV interregional scientific and practical conference. Sevastopol state University; scientific ed. by B. V. Sokolov. 2018. P. 339-341 (in Russian).

[2] Skryl' S.V., Le Vu Huong Zang, Nguyen Thanh Nyan Productive characteristics of the specialists' preparation. The bulletin of Voronezh Institute of the Ministry of Internal Affairs of Russia. 2015. Vol. 3. P. 64-71. URL: $\quad$ https://cyberleninka.ru/article/n/pokazateli-effektivnosti-protsessa-podgotovki-spetsialistov/viewer (accessed: 07.10.2020) (in Russian).

[3] Skryl' S.V., Ponomarev V.A., Hyong Zang Le Vu, Ivanova O.G. Mathematical models of comprehensive evaluation of the quality of the preparation of technical specialists in higher educational institutions. Industrial Automatic Control Systems and Controllers. Scientific \& Technical Literature Publishing House

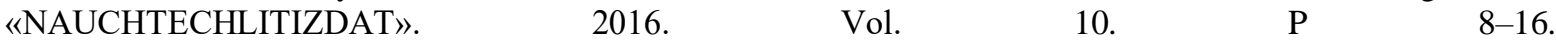
URL: https://elibrary.ru/item.asp?id=27180767 (accessed: 07.10.2020) (in Russian).

[4] Zelentsova E.V., Le Vu Hyong Zang et. al. Methodical recommendations on systematic procedure of the specialists' preparation quality features // Scientific view: The International scientific-practical conference proceedings. - M.: Moscow State Regional University, 2015. P. 225-230 (in Russian).

[5] Skryl' S.V., S.A. Barkalov, Le Vu Hyong Zang, V.A. et al. System Structure Characteristics of Quality Activities in Specialists' Preparation in Higher Education Institutions. Industrial Automatic Control Systems and Controllers. Scientific \& Technical Literature Publishing House «NAUCHTECHLITIZDAT». 2016. Vol. 9. P. 11-15. URL: https://elibrary.ru/item.asp?id=26702710 (accessed: 07.10.2020) (in Russian).

[6] Dortman, Svetlana Information Security of the Child as a Subject of the Educational Process // Protection of childhood: problems, searches, solutions collection of materials of the all-Russian scientific and practical conference dedicated to the Decade of childhood in Russia. 2018. P. 315-319. URL: https://ssrn.com/abstract=3469614 (accessed: 07.10.2020) (in Russian).

[7] Skryl' S.V. et al. Mathematical model to assess the effectiveness of training specialists in information security based on time characteristics of the educational process. Industrial Automatic Control Systems and Controllers. Scientific \& Technical Literature Publishing House «NAUCHTECHLITIZDAT». 2020. Vol. 1. P. 28-35. DOI: http://dx.doi.org/10.25791/asu.1.2020.1118 (in Russian).

[8] Nadezhdin E.N., Sheptuhovsky V.A. Methodical method for information security risks assessing in computer networks of educational institutions. Educational Informatics. 2012. № 4. P. 84-92. DOI: http://dx.doi.org/10.25791/asu.1.2020.1118 (in Russian).

[9] Nadezhdin E.N., Sheptuhovsky V.A. Algorithmic approach to assessing information security risks in educational institutions // Scientific research. 2013. №2.5. P. 2-27 (in Russian).

[10] Tscherbakov N.P. Improving the quality assessment system of higher education. N.P. Tscherbakov. Quality assurance of professional education: abstracts of reports of the international scientific and practical conference [ed.: Ya. L. Ovchinnikov et al.]. Barnaul: AltSTU Publishing house,2015. P. 9-11 (in Russian).

[11] Guzairov M.B., Mashkina I.V., Stepanova E.S. Building a threat model using fuzzy cognitive maps based on network security policy. ITSecurity. 2011. № 2. P. 37-49 (in Russian).

[12] Rabai L.B., Rjaibi N., Aissa A.B. (2012) Quantifying security threats for E-learning systems. DOI: https://doi.org/10.1109/ICEELI.2012.6360592.

[13] Skryl' S.V. et al. (2019) Assessing the Response Timeliness to Threats as an Important Element of Cybersecurity: Theoretical Foundations and Research Model. In: Kravets A.G. et. al. (eds) Creativity in Intelligent Technologies and Data Science. CIT\&DS 2019. Communications in Computer and Information Science, vol 1084. Springer, Cham. DOI: https://doi.org/10.1007/978-3-030-29750-3_20.

[14] Dolzenko A.I., Potapov L.I. Analysis of information security of the University educational process based on fuzzy models / SOFT MEASUREMENTS AND COMPUTING. Vol. 30, No. 5, 2020. P. $32-40$. URL: https://elibrary.ru/item.asp?id=43929605 (accessed: 07.10.2020).

[15] Gorbatov, Victor Sergeevich et al. Statement of the Problem on Implementing a Trusted Communications Session in E-learning Systems. IT Security (Russia), [S.1.]. Vol. 20. No. 3. P. 104-105, 2013. ISSN 2074-7136. URL: https://bit.mephi.ru/index.php/bit/article/view/328 (accessed: 07.10.2020) (in Russian).

[16] Tuliganova L.R., Pavlova I.A., Mashkina I.V. Development of models of the protection objects and security threats in an information system based on virtualization technology. News of the southern Federal University. Technical Studies № 8 (157). Taganrog, 2014. P. 32-41 (in Russian).

Поступила в редакцию - 07 октября 2020 г. Окончательный вариант - 01 ноября 2020 г. Received-October 07, 2020. The final version - November 01, 2020. 